\title{
Solidity, Leverage and the Regulation of Insurance Companies *
}

\author{
by Yehuda Kahane **
}

\section{Introduction}

Various forms of regulation are applied to protect the solidity of insurers and to restrict their probability of ruin. The most popular ways for regulating the insurer's solidity are constraints on its "leverage" (the ratio between the premiums and the equity) and other related ratios (e.g., assets/equity, liabilities/equity, etc.). The leverage constraints often take the form of a minimum capital requirement. ${ }^{1}$ Other common regulatory means take the form of constraints on the composition of the asset and liability portfolios of intermediaries. The purpose of this study is to examine the effectiveness of regulatory policies and their adequacy for guaranteeing the soundness of the insurer's financial position.

Three distinct models are examined in an attempt to shed additional light on the problem from various points of view. The first two models analyze the problem of ruin within a discrete time period through the application of the instruments of portfolio theory. The analysis is based on the proposition that capital requirement must be related to the overall performance of the insurance company. The overall performance is a function of both underwriting and investment incomes and their risks. By including investment income and investment risk we extend Hammond, Shapiro and Shilling [1978] analysis which takes into consideration only the underwriting income and its risk.

Hammond et al focused on the underwriting activities in isolation because "... any attempt to analyze insurer investment and underwriting interaction is greatly com-

* A study prepared for the "Geneva Association"; revised version received in December 1978.

** Academic Director, Erhard Insurance Center, Faculty of Management, Tel Aviv University, Israel.

1 The rules may take the form of either a mandatory requirement or guidelines used in the examination of financial statements (which may create the same effects as a mandatory requirement). For example, an insurer may be classified in a "bad range" once the leverage exceeds a certain value, e.g. 2 or 3 (Beckman and Tremeling [1972, p. 213]). The National Association of Insurance Commissioners in the U.S. suggests that insurers should avoid leverage ratios which exceed 2 (NAIC [1970]). The N.A.I.C. approach can be traced back to the early study of R. Kenney [1967]. Kenney studied company failures during the Great Depression and suggested some forty years ago that casualty insurers should avoid leverage ratios which exceed 2, and that fire insurers should keep the ratio below 1. The New York Insurance Department allows a ratio of up to 3.3, and other authorities allows a ratio of up to 4. Hofflander and Duvall [1967, 151, f.n. 3] suggested the replacement of the Kenney ratio by a set of ratios established by English companies. They used the cover ratio (total assets divided by premiums written). A ratio above 1.25 is considered highly desirable whereas a ratio lower than that is undesired. It can, however, be shown that the cover ratio is directly related to the Kenney ratio rule; for example, a stipulation that the cover ratio be 1.25 or higher, when reserves are approximately equal to the premiums, is equivalent to the requirement that the Kenney ratio be less than 4 . 
plicated by the fact that it is extremely difficult to generate accurate estimates of investment returns associated with each line of insurance..." [1978, p. 18]. Our first model overcomes this difficulty by analyzing a simple case where the insurer has only one insurance and one investment activity and examines the role of insurance leverage. The second model examines the complex case where the company is operating in several insurance and investment activities and presents another way to overcome Hammond's problem. This model which follows Kahane [1977], adds a new dimension to the regulatory problem by bringing out the effects of diversification of the insurer's book of business. It makes possible the study of the simultaneous effects of both the leverage and the portfolio composition on the probability of ruin. Both models are used to demonstrate that the existing forms of regulation do not necessarily reach their stated goals.

The third model examines the problem from a completely different point of view. This time the insurer is assumed to have only one insurance activity, but the analysis is carried within a continuous time framework. Following Tapiero, Zuckermann and Kahane [1978], it is argued that the desired regulatory effects can be achieved by introducing a set of penalties rather than through the direct interference in the firm's activities.

\section{Model I : Single insurance and investment activities, discrete time}

In this section the ruin problem of a general non-life insurance company is examined under relatively simple conditions. It is assumed that the firm is limited to a single type of insurance activity and one investment. Under such a simplified case the firm can control its profitability and risk only by changing the amount of premiums it sells with a given capital - i.e., by changing the "leverage". A definition of ruin is proposed under the assumption that ruin can occur only at a certain date - e.g., at the end of the examined period. The relationships between the firm's leverage and its probability of ruin is then examined, followed by the analysis of the impact of regulation.

\subsection{The Efficiency Frontier}

The insurer, like other firms, faces the choice between various business strategies which can be summarized as a choice between profitability and risk. The finance literature recommends the use of the expected return as a measure of profitability and the standard deviation as a risk measure. The "efficient" strategies are those which have the minimal standard deviation for any level of expected value. ${ }^{2}$ The locus of

2 The application of the mean-variance approach to the determination of the efficiency frontiers is appropriate under the assumption that the relevant distributions are normal (Levy and Sarnat [1972, ch. 11]). This seems to be quite a reasonable assumption for the case of insurance companies; the return on each policy or investment activity may even have a skewed distribution, but the distribution of the return on highly diversified assets and liabilities portfolios is approximately normal according to the law of large numbers. The normality assumption is often used in the insurance context (see for example, the recent study of Hammond et al [1978]). 
these strategies can be described graphically by a curve like $F F^{\prime}$ in Figure 1 (the " Efficiency Frontier").

Profitability (Expected Return)

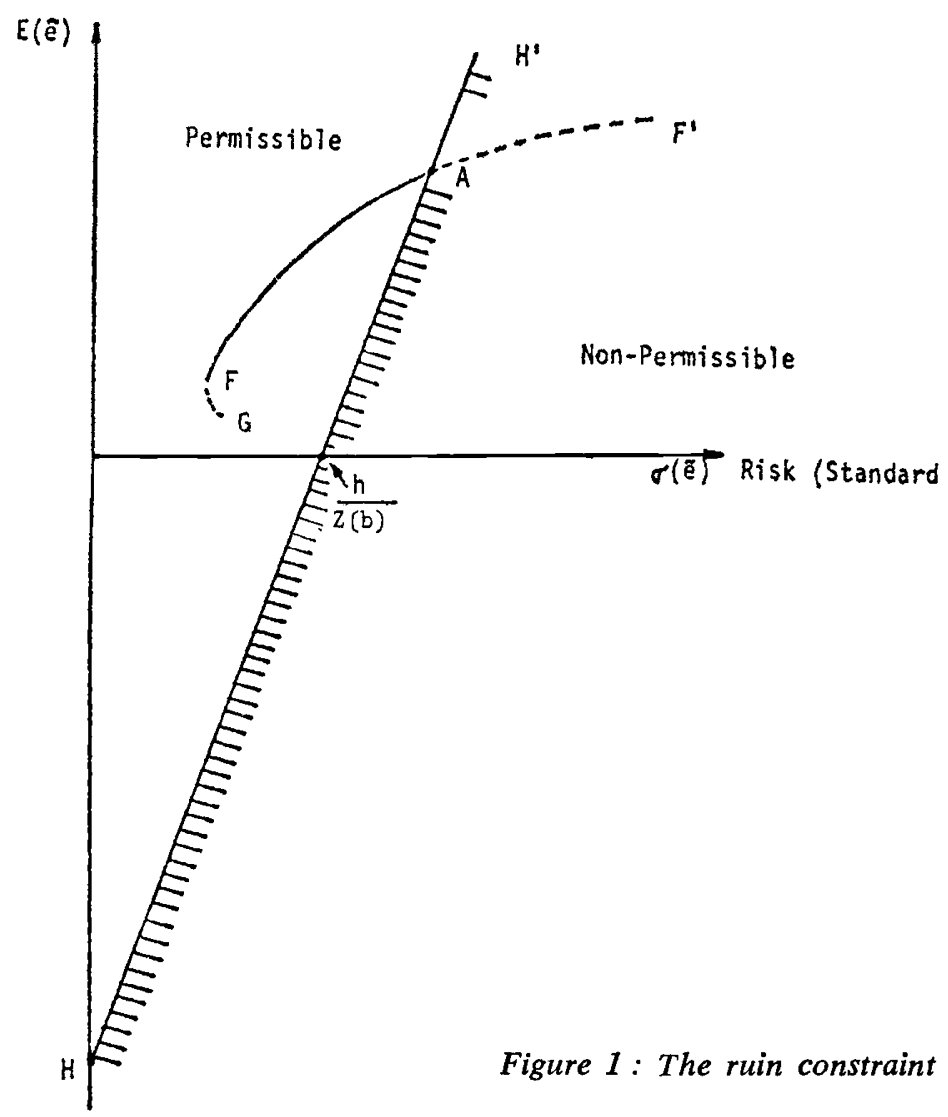

Consider an insurer who is engaged in only one insurance activity and has a single investment opportunity. The total earnings for that period, $\widetilde{Y}$, is :

(2 - 1)

$$
\widetilde{Y}=\widetilde{U}+\widetilde{I} \text {. }
$$

Where $\widetilde{U}$ and $\tilde{I}$ denote the aggregate underwriting and investment profit respectively. Denoting the premiums by $P$ and the assets by $A$, the rate of underwriting profit is $\widetilde{r_{1}}\left(\widetilde{r_{1}}=\widetilde{U} / P\right)$ and the return on the investments is $\widetilde{r_{2}}\left(\widetilde{r_{2}}=\widetilde{I} / A\right)$. The rate of return on the equity, $e$, is obtained from $(2-1)$, as follows :

$$
\tilde{e}=\frac{\tilde{Y}}{S}=\frac{P}{S} \tilde{r_{1}}+\frac{A}{S} \tilde{r_{2}}
$$


The insurer is assumed to have equity capital $S$ (book value is assumed to equal the market value). The reserves of the firm are assumed to be equal to a certain multiple of the premiums. This represents the assumption that each dollar of premiums generates $g$ dollars of reserves. ${ }^{3}$ Thus, the balance sheet equality can be expressed as :

$$
A=S+g P \text {. }
$$

The rate of return on the equity, $e$, is obtained from $(2-2)$ and $(2-3)$ :

$$
\widetilde{e}=k \widetilde{r}_{1}+(1+g k) \tilde{r_{2}},
$$

where $k$ denotes the premiums written per dollar of equity $(k=P / S)$, often called the "Kenney Ratio" or "insurance leverage". The only decision variable in $(2-4)$ is the leverage, $k$. The insurer's profit and risk are fully determined by the leverage ; the profitability of the firm is measured by the expected return on equity.

$$
E(\tilde{e})=k E\left(\tilde{r_{1}}\right)+(1+g k) E\left(\widetilde{r_{2}}\right) \text {, }
$$

where $E$ is the expected value operator. The variance of the return on equity is

$$
V(\tilde{e})=k^{2} V\left(\tilde{r_{1}}\right)+(1+k g)^{2} V\left(\tilde{r_{2}}\right)+2(1+g k) k \operatorname{COV}\left(\tilde{r_{1}}, \widetilde{r}_{2}\right),
$$

where $V$ denotes variance, and $\operatorname{COV}\left(\widetilde{r_{1}}, \widetilde{r_{2}}\right)$ denotes covariance between the return on investment and the underwriting profit. 4 Equations $(2-5)$ and $(2-6)$ describe the opportunity set, i.e., all the possible combinations of expected return and standard deviation which a company can achieve by varying the degree of leverage $k$. This set is described by the curve $F F^{\prime}$ in Figure 1 . The exact shape of this curve is studied later in this paper.

\subsection{Profitability and solidity}

The relationships between the profitability of the insurance company and its solidity is now examined. "Ruin" is defined to be a situation whereby the rate of return on the equity, $e$, which is a random variable, falls below a certain level $h$. Setting the regulatory solidity standard is equivalent to determining the level of $h$ and an upper bound, $b$, on the probability of ruin, so that

$$
P\{e \leqslant h\} \leqslant b .
$$

Rewritting in a standardized form leads to

$$
P\left\{\frac{\tilde{e}-E(\tilde{e})}{\sigma(\tilde{e})} \leqslant \frac{h-E(\tilde{e})}{\sigma(\tilde{e})}\right\} \leqslant b .
$$

3 This technical parameter (the funds generating coefficient, $g$ ) may sometimes be larger than unity, to represent a case where the outstanding claims together with unearned premium reserves exceed the premium.

4 It is noteworthy that when the variances are estimated empirically, the correct risk measures would be the temporal variances (i.e., the variances of the insurer's own underwriting and investment results over a period of time). Only when no such data are available, one might use variances obtained from a cross section of the industry to get a rough estimate of the risks. This may be the case when analyzing a new insurer entering the industry. (See Hammond et al [1978].) 
Assuming that $\widetilde{e} \sim N(E(\widetilde{e}), \sigma(\tilde{e}))$, one can use the tables of the normal distribution in order to find a constant $z(b)$ which fulfills ${ }^{5}$

$$
\frac{R-E(\tilde{\mathrm{e}})}{\sigma(\tilde{e})} \leqslant z(b),
$$

or

$$
E(\tilde{e}) \geqslant h-z(b) \sigma(\tilde{e}) .
$$

The solidity requirement $(2-10)$ determines the risk-return combinations that should not be employed by the company. Inequality $(2-10)$ defines a half-plane bounded by a straight line (line $H H^{\prime}$ in Figure 1).

There is no uniform agreement on the severity of the loss that can be defined as ruin. However, defining "ruin" as $h=100 \%$ has a special intuitive appeal in the single period analysis. This means that ruin occurs when the equity is completely eliminated. ${ }^{6}$

Figure 1 shows that the ruin constraint may intersect with the efficiency frontier. The intercept enables to distinguish between permissible and non-permissible strategies. In Figure 1, for example, the firm would be permitted to operate only in section $F A$ of the efficiency frontier. There is a direct relationship between the degree of leverage and the expected return. Thus the intercept can be interpreted also as defining a range of permissible leverage. As a consequence, the probabilistic ruin constraint can be translated directly into a more practical constraint, such as a constraint on the insurer's leverage. The conditions under which such a translation is allowed are studied next through the analysis of the nature of the efficiency frontier.

\subsection{The shape of the frontier and the implications for regulation}

The efficiency frontier is described by a quadratic equation (which is typically hyperbolic). This happens since $E(\tilde{e})$ is linear with the leverage $k$, while $V(\widetilde{e})$ is quadratic with $k$. This can be easily shown by analyzing $(2-5)$ and $(2-6)$ : Rewriting $(2-5)$ shows that $E(\tilde{e})$ is function of the leverage $k$.

$$
E(\widetilde{e})=E\left(\widetilde{r_{2}}\right)+k\left[g E\left(\tilde{r_{1}}\right)+E\left(\widetilde{r_{2}}\right)\right] .
$$

$E(e)$, therefore, increases with $k$ if

$$
g E\left(\tilde{r_{1}}\right) \geqslant-E\left(\widetilde{r_{2}}\right)
$$

Similarly, expressing the variance $(2-6)$ as a function of $k$ leads to

$$
V(\tilde{e})=2 g \operatorname{COV}\left(\tilde{r_{1}}, \tilde{r}_{2}\right) k^{2}+\left[2 g V\left(\tilde{r_{2}}\right)+2 \operatorname{COV}\left(\tilde{r_{1}}, \widetilde{r}_{2}\right)\right] k
$$

or,

$(2-14)$

$$
V(\widetilde{e})=a k^{2}+b k+c .
$$

5 The probability $b$ must typically be low so $z(b)$ is highly negative and the ruin constraint line will be positively sloped.

6 Such a definition is taken by Borch [1974], Hofflander and Duvall [1967] (implicit in their equation (8)) and Hammond et al [1978]. 
$V(\tilde{e})$ is quadratic with $k$, and reaches a local extremum at $k=-b / 2 a$. This can be shown to be a minimum so that the efficient frontier must be concave.7

Due to the quadratic shape of the efficiency frontier and its concave nature there may be no intercept, or at most two intercepts, with the ruin constraint. This may give rise to various forms of solidity regulation through constraints on the leverage.

(a) Only one intercept between the ruin constraint and the frontier :

Here there are two possibilities, depending on the shape of the frontier :

$i$. Expected return increases with leverage : Curve $A B C$ in Figure 2a demonstrates the case where the expected return on equity increases with $k$. Any combination in section $A B$ (where the variance decreases with $k$ ) is clearly inefficient because it is dominated by point $B$ which represents a higher expected return with a lower variance. Beyond point $B$, any further increase in the leverage increases both the expected return and the variance. Assuming that there is only one intercept of the efficiency frontier with the ruin constraint, the frontier is divided into two sections; the points on section $B C$ comply with the ruin constraint ; the upper section, $C D$, however, is regarded too risky and is non-permissible. In such a case the probabilistic ruin constraint can be translated into a constraint on the leverage : the use of leverage above the level in point $C$ should be prohibited.

ii. Expected return decreases with leverage: A more peculiar case is when the expected return decreases with $k$. Curve $A B D$ in Figure $2 \mathrm{~b}$ represents the opportunity set in this case. Section $C D$ lies in the prohibited region and this section represents the lower degrees of leverage. The ruin constraint should be translated into a regulation which prohibits the use of leverage below ruin level in point $C$. Moreover, a regulation which imposes an upper limit on the leverage is redundant if the regulated limit is above the degree of leverage in point $B$, since the section $A B$ is anyhow inefficient and the firm will not use a higher degree of leverage even without the regulation.

This case will not be discussed further, since it seems to be quite unrealistic; such situations occur when the expected rate of underwriting profits is highly negative, and the present situation of the insurance industry does not seem to support such an assumption (see Joskow [1973], Quirin [1974]). Moreover, in equilibrium, the underwriting profits must be determined so that there will be some overall positive profit and this violates the condition $(2-12)$ (see Kahane [1978]). We shall concentrate therefore on the case in which the expected return increases with $k$ (Figure 2a).

(b) Two intercepts with the efficiency frontier :

Another peculiar case is when the ruin constraint has two intercepts with the efficiency frontier. This may be a result of the concave nature of the latter (see Figure

7 The concavity of the envelope curve may also be affected by changes of the returns on individual activities caused by leverage changes : a leverage increase for a given capital means more insurance selling. This may be accomplished by insuring the marginal and less profitable policies which, in turn, reduces the expected underwriting profits. In the same way, the return on investment may also decrease when more investments are made (see Ferrari $[1969$, p. 59]). The immediate effect is that the expected return on equity must be non-linear with $k$. 

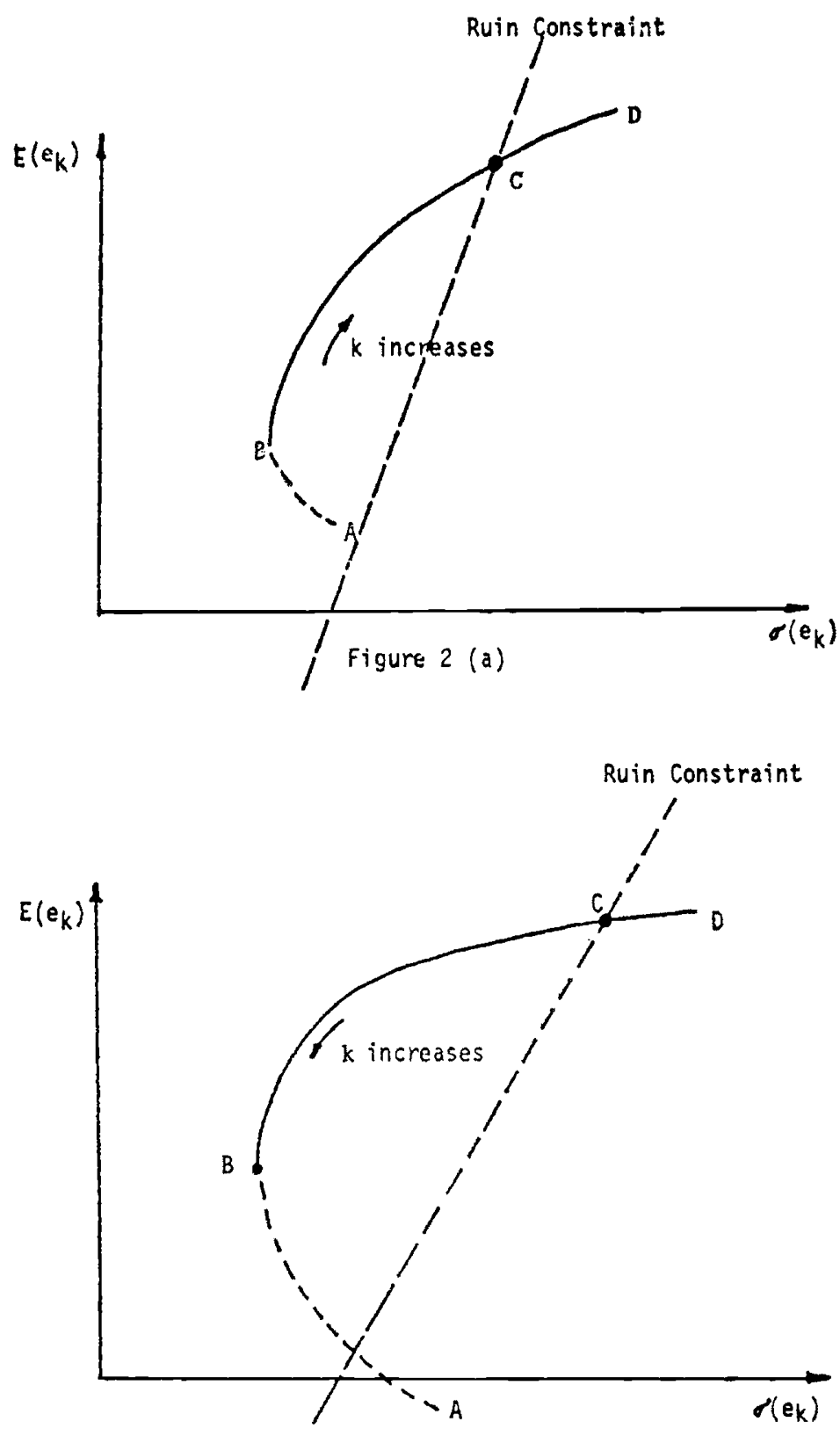

Figure 2 (b)

Figure 2: The general shape of the opportunity curve 
3). In this particular case, the regulator should set both an upper and a lower bound on the insurers' leverage. The company should be advised to operate with intermediate levels of leverage (leverage between those in points $B$ and $C$ ).

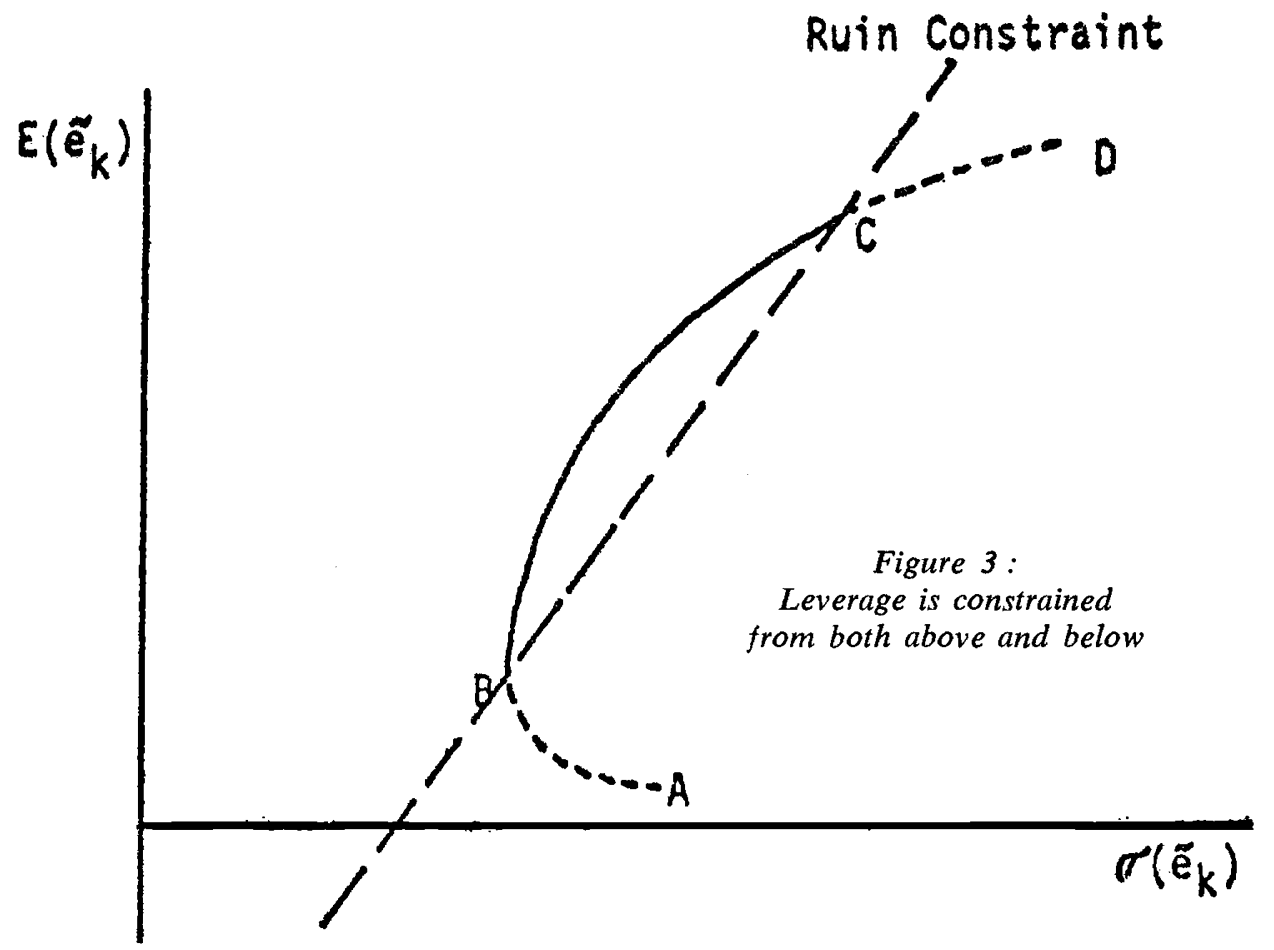

Intuitive considerations suggest that such a case would be quite rare and therefore is of little practical interest. This case may occur when the concavity is noticeable as a result, for example, from a strong negative correlation between $\widetilde{U}$ and $\widetilde{I}$. Also, the hyperbolic nature of the opportunity set implies that as $k$ increases the frontier becomes asymptotic to a straight line. Therefore, if the ruin constraint intersects the opportunity set twice, one of the points is probably at a very low leverage (in the inefficient part of the frontier).

The analysis of the simplified case, where there is only one insurance and one investment activity has shown that an imposition of an upper constraint on the leverage is a reasonable practice except in a few rare cases. In the next section, however, a more complex case is analyzed, and reveals some deficiencies of such a regulatory method.

\section{Model II : Multiple insurance and investment activities, dlscrete time}

In this section, the regulation is considered from a broader point of view, where the firm has a multiple-line activity, but we still remain in the framework of a discrete 
time analysis. The model follows the analysis by Kahane [1977], and utilizes a portfolio approach which was discussed in Haugen and Kroncke [1971], Hart and Jaffee [1974], Kahane and Nye [1975], Krouse [1970], Parkin [1970], Pyle [1971], Quirin et al [1974] and others.

Assume an insurance company which considers selling $m$ various insurance policies, and invest in $n-m$ types of assets. The returns on these activities are random variables $\widetilde{r}_{i}$ with known (and approximately normal) distributions. The return on equity, $\tilde{e}$, is a linear combination of these random variables and therefore is by itself normally distributed

$$
\text { (3-1) } \quad \tilde{e}=\sum_{i=1}^{n} \tilde{a}_{i} r_{i},
$$

where

$$
r_{i}=\left\{\begin{array}{c}
\text { rate of profit on } i \text {-th insurance policy (percent of premium) for } \\
i=1,2, \ldots, m . \quad \text { and } \\
\text { rate of return on investment } i \text { (percent of the assets) for } \\
i=m+1, m+2, \ldots, n
\end{array}\right.
$$

$a_{i}=\left\{\begin{array}{l}\text { ratio of premium of policy } i \text { to equity }(i=1,2, \ldots, m), \text { and } \\ \text { ratio of investment in asset } i \text { to equity }(i=m+1, m+2, \ldots, n)\end{array}\right.$

$$
a_{i} \geqslant 0(i=1,2, \ldots, m, \ldots, n) \text {. }
$$

The terms $a_{i}$ will be considered as the decision variables of the firm. That is, the firm has to select the vector of $a_{i}$ which satisfies an objective function which is specified below. ${ }^{8}$

Note that in a previous development of the model (Kahane [1977]), $a_{i}(i=1, \ldots, m)$ were related to the entire insurance line rather than to individual policies. This clearly reduced the size of the problem at hand, but involved a somewhat unrealistic assumption that the parameters for the entire line are independent of its size (which indirectly meant that the profit on all policies in that line are perfectly positively correlated).

This approximation could be acceptable for practical purposes if an additional policy does not change drastically the risk of the line ${ }^{9}$. Such an aggregation is required in order to reduce the size of the computational problem to a manageable level.

8 Each decision variable $a_{i}$ may obtain any non-negative values, but is not constrained to be either an integer or in the range $(0,1)$. It means that the firm is able to sell any insurance policy, with a large or small premium. If the desired $a_{i}$ does not match the size of the original contract, it is always possible to sell a fraction of the insurance policy to a reinsurer through a proportional reinsurance arrangement. However, it is assumed that the basic parameters $E\left(\widetilde{r_{i}}\right)$ and $\sigma\left(\widetilde{r_{i}}\right)$ remain constant even for a fraction of contract. In order to prevent the $a_{i}$ from getting an excessive value, it is possible to introduce upper bounds on the values of the variables $a_{i}$, at least for the insurance transactions.

9 The coefficient of variation of the underwriting results for one insurance policy, for example, would be much larger than the coefficient of variation of the underwriting results for a large portfolio (the Law of Large Number takes effect). 


\subsection{The Efficiency Frontier}

It is assumed that the insurers wish to minimize the variance of the rate of return on their equity for any level of expected value ${ }^{10}$. Thus, the objective function is to find a composition of the weights $a_{i}$ so that

$$
\operatorname{Min} L=\operatorname{Var}(\tilde{e})-\lambda E(\tilde{e})
$$

where

$$
E(\tilde{e})=\sum_{i=1}^{n} a_{i} E\left(\tilde{r_{i}}\right)
$$

and the variance of the return on equity is

$$
\operatorname{Var}(\tilde{e})=\sum_{(i, j)=1}^{n} a_{i} a_{j} \operatorname{Cov}\left(\tilde{r_{i}}, \tilde{r}_{j}\right)
$$

The unknowns $a_{i}$ must be determined in a way such that the total assets minus the liabilities equals the equity. Thus, the optimization is subject to the additional balance sheet constraints (see Kahane [1977]), and other constraints which will not be discussed here.

Solving this problem generates the efficiency frontier for the firm, i.e., the locus of the best risk-return combinations for the firm. Each point along this curve represents a certain composition of insurance and investment portfolios which gives the lowest standard deviation for any given level of expected return. The expected return on equity, and its standard deviation determine the firm's solidity. This model is, therefore, used below to evaluate the adequacy of the rules used by regulators for the protection of insurance companies solidity. The analysis follows the same line as in Model I.

\subsection{The regulation of leverage}

In examining the effectiveness of the constraints on the leverage of insurance companies, it is useful to describe the efficiency frontier as an envelope of the individual frontiers obtained with predetermined levels of leverage. For that purpose, the optimization problem $(3-2)$ is solved with an additional constraint which keeps the leverage, $k$, at a constant level $k_{o}$. The leverage is represented by the sum $\sum_{i=1}^{m} a_{i}$, which is the amount of premiums written for each dollar of equity. The constraint takes the form :

$$
\sum_{i=1}^{m} a_{i}=k_{o} \text {. }
$$

The above procedure generates a distinct efficiency frontier for each level of leverage, $k_{o}$. Repeating this process for different values of $k_{o}$ generates a set of efficiency frontiers (see Figure 4). When the problem is solved without the constraint $(3-5)$ we obtain an envelope frontier which is tangent to these curves (Kahane and Nye [1975],

10 This paper analyzes the probability of a ruin which depends on both the "systematic" and "unsystematic" fluctuations of the firm's earnings. Thus, the variance is used as a measure of risk rather than the well-known "beta" coefficient (systematic risk measure). 
Quirin et al [1974]). A movement along the envelope curve (curve $F C F^{\prime}$ in Figure 4) means a change in the degree of leverage in addition to changes in the composition of insurance and investment portfolios.

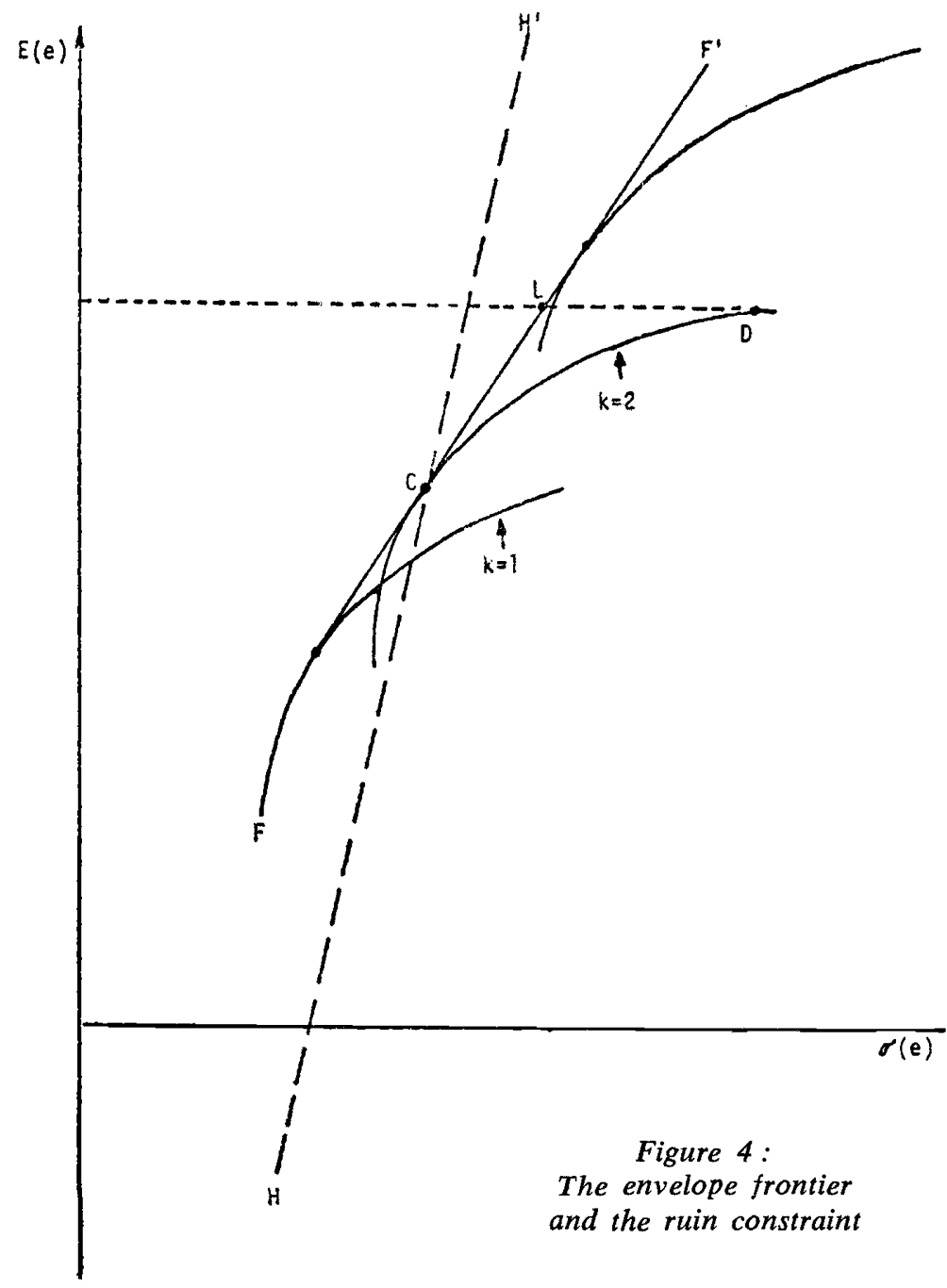

Once again, the ruin constraint (equation $2-10$ ) is superimposed (see line $H H^{\prime}$ in Figure 4). As evident from Figure 4, the ruin constraint cannot now be directly translated into a constraint on the leverage : constraining the leverage turns to be an ineffective means for bounding the probability of ruin. Assume that point $C$ in Figure 4, which is the intercept of the unconstrained frontier, $F C F^{\prime}$, with the ruin constraint corresponds to a leverage $k^{*}\left(k^{*}=2\right.$ in the specific case in Figure 4). Using $k^{*}$ as the 
regulatory constraint means that the new frontier is obtained by solving $(3-2)$ subject to the additional constraint :

$$
\sum_{i=1}^{m} a_{i} \leqslant k^{*}
$$

The resulting frontier is described by curve $F C D$ in Figure 4 . This frontier is a combination of section $F C$ of the unconstrained frontier, plus section $C D$, where the new constraint is binding.

The insurer may, thus, hold a portfolio $D$ which complies with the leverage constraint $(3-6)$ but clearly does not comply with the ruin constraint (e.g. Portfolio $D$ lies below the ruin constraint $H H^{\prime}$ ). The insurer is thus able to reach an excessive risk level despite the regulation. Moreover, the regulation encourages the insurer to hold an inefficient portfolio: without regulation the insurer may hold a portfolio with the same expected profit but a lower variance (e.g., portfolio $L$ instead of $D$ ).

\subsection{Regulation of the portfolio composition}

Similarly, constraints on the portfolio composition turn out to be ineffective, too. Such constraints truncate the efficiency frontier at each level of leverage and shift it downward and to the right ; for a given leverage ratio $k$, the constrained frontier $A B C$ in Figure 5 is shifted to the lower level $D E F$. As long as the insurer is free to set the degree of leverage, the relevant shift is from the envelope IBJ to $G E L$. The regulatory goal, however, is not reached since the insurer may indefinitely increase the expected return on equity and its standard deviation by simply increasing the leverage. Thus, he may hold a portfolio with excessive probability of ruin (e.g., point $L$ in Figure 5).

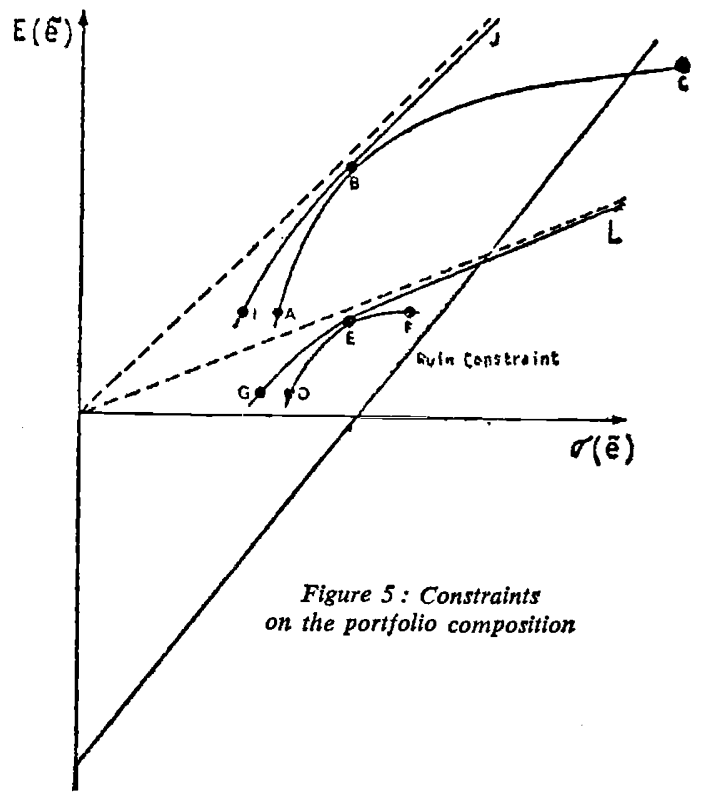


It becomes clear that minimum capital requirements or constraints on the portfolio composition, per se, cannot be regarded as effective means of bounding the probability of ruin. This goal can be reached only by simultaneously using the two instruments.

\section{Model III : Penalty system, continuous time framework}

The two models presented above disregard the set of penalties which regulators introduce in practice. In this section it is argued that the penalties can be regarded as an important regulatory instrument, and that much care should be given to the selection of the optimal punitive system. This argument is supported by a model which clearly takes into consideration the punitive system.

There are also technical differences between the model described in this section and the earlier models : the discrete time framework used in the first two models is replaced by a continuous time framework. In addition, the assumption of the normal claim process is relaxed and replaced by the more general compound Poisson process. Dealing with a problem of such a complexity leads to a very complicated mathematical analysis. The problem is, therefore, simplified somewhat by neglecting the case of multiline activities which has been discussed in the second section and returning to that of a single activity.

The model in this section follows the idea of a "survival model" in a continuous time framework, which has been discussed for example by Bühlmann [1971] and Hallin [1977] and the references mentioned therein (especially Borch, De Finetti and Gerber). A somewhat broader model has been presented recently by Tapiero, Zuckermann and Kahane [1978] (hereafter TZK). The discussion in this section follows the TZK model and, therefore, only summarizes their major assumptions and results, while not duplicating the details of the complicated mathematical formulation.

The novelty in the TZK approach is in the use of a new definition of "ruin"; in previous models, once a firm violates the regulatory standards it is regarded as "ruined", and forced to go out of business. In the TZK analysis such a situation involves a payment of a "penalty", which enables the firms to resume operation. The penalty may take various forms : a fine, extra cost of reorganization, etc. Such a model gives a better description of reality, since insurers, after being practically ruined, often resume operation, by the way of merger, purchase, or reinsurance. This solution may also be regarded a more reasonable one since ruin situations can result from the random nature of the claims and reserves processes, and continuing operation after practically being ruined may enable the firm to recover in the long run. The TZK model integrates the penalty cost among the factors considered by management when selecting its optimal strategy.

The basics of the TZK model are as follows : the firm's reserve process is affected by incoming premiums and by the payment of claims. Premiums are assumed to arrive at a constant rate which is equal to the expected claims rate plus a proportional loading factor. ${ }^{11}$ Claims are assumed to occur at a Poisson rate $\lambda$ with successive claim

11 Administrative expenses are included together with claims. The loading factor represents only an expected underwriting profit. A possible extension of the model, which is not repeated here, may extend the analysis by including the loading factor among the decision variables of the firm. 
assumed positive, independent and identically distributed random variables (with a mean $\xi$ ). The net reserve of the firm at any point in time is composed of the initial reserve plus the difference between the premiums and the claims.

The reserve process is subject to some constraints which give the grounds for an optimization problem. On the one hand there is a minimum reserve level, $K$, required by the regulator. Violating this capital requirement involves a penalty against the firm. The penalty may be a combination of several elements : For example, it may consist of a fixed cost element for the downcrossing $k$, and a variable cost proportional to the size of the jump below $K$. The variable cost may be regarded as the cost of a "loan" given to a failing firm so that it returns immediately to the reserve level $K$. Alternatively, this may represent the cost of converting other assets into the form of cash. The model can easily be extended to handle additional costs : for instance, the costs of situations with negative reserves.

The firm would be interested to hold net reserves greater than $K$ to avoid the case of incidental downcrossing of the regulatory standard. However, the firm refrains from holding an infinite reserve since holding such cash reserves involves an opportunity cost (in the form of an interest rate, $r$ ). ${ }^{12}$

A decision variable (a barrier policy), $A$, must therefore be introduced. This variable denotes the initial level of reserves. Any reserve above this level incures a cost $r$. If the reserve falls below $A$ the firm retains all net accumulation of premiums and keep it in the form of cash. If the reserves fall below the minimum capital requirement, $K$, there is a penalty and the firm automatically returns to reserve level $K$. (See Figure 6 for a graphical description of the process.)

The long-run profit of the firm is a function of the minimum reserve, $K$, the cost elements, and the barrier strategy A. Using the tools of control theory this function can be specified and studied. From this it is possible to derive formally some quantities

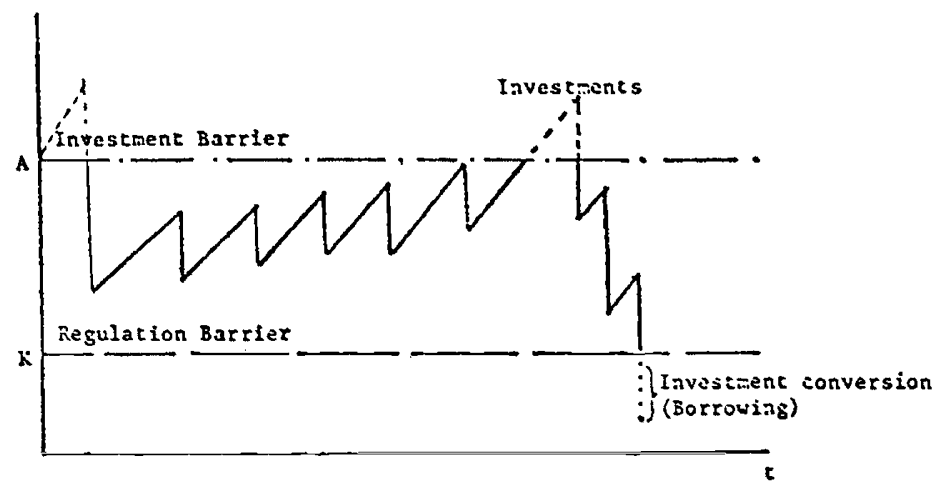

Figure 6: Ruin as a band strategy problem

12 Alternatively, it can be assumed that the surplus is distributed as dividends and drawn out of the system. Holding cash reserves incures the opportunity cost of non payment of dividend. 
of interest such as the expected time between the events of downcrossing the regulatory standards. The expected long-run profit can be specified, and the optimal strategy $A$ can be found. The formula is developed and reported in TZK (equation 2 - 4). The mathematical expansion is quite complicated and even when the parameters are given and the claim distribution is known, it is often necessary to rely on numerical methods to find the optimal strategy.

The penalties are introduced into the system in order to internalize the external cost of bankruptcy. If the cost of ruin considered by the management is lower than the cost from a societal point of view, the firm's policy would be to take " excessive" risk. The regulators problem should, therefore, be aimed toward equating the external and internal costs.

Notice that the size of the penalty may affect the reserve level, $A$. It appears that this relationship is often disregarded by regulators since the penalty system is determined in an arbitrary way. The model can be used to assist the regulator in determining the " optimal" penalty, in the sense that this would be the lowest penalty for a given probability of ruin.

Regulators set both the minimum capital requirement, $K$, and the penalty for downcrossing this requirement. This parameters would typically motivate the firm to hold a reserve, $A$, larger than the required minimum $(A>K)$. Thus, if the regulator prefers to have a certain reserve level, he should determine a lower minimum capital requirement.

There is a certain trade-off between the minimum capital requirement and the size of the penalty, in the sense that different policies may lead to the same reserve level, $A$, and thus to the same probability of ruin. Regulators may prefer to increase the penalties because of political considerations : a high minimum capital requirement may force the companies to take immediate steps and increase their capital, which may create some political pressures against the regulator.

Viewing the firm's decision under this model may give some insight into the problem of regulation: It is the purpose of regulation to prevent deliberately caused ruin, and this can be achieved by introducing a potential penalty (i.e., a "threat") into the system. Management would take this penalty into consideration in their decision making. Empirical studies show that one of the major reasons for the failure of banks and financial intermediaries was fraud. The common regulatory techniques, including the leverage constraints, are ineffective in preventing this type of ruin. A penalty system, which weakens the protection given to management by the "limited liability" idea, may serve as a better deterrent against ruin caused by fraud.

\section{Summary and concluding remarks}

Three alternative models were discussed in the paper, and each one was used to shed light on the problem of the regulation of insurers solidity from a different point of view.

The first model is based on a simplified case where only one insurance and one investment activity are considered, in a discrete time framework. In this case there is some justification for constraining the degree of leverage used by the firm. The 
analysis shows that there are, however, some cases where regulators should prohibit levels of leverage which are too low, and in other cases the leverage should be constrained between an upper and a lower limit. These cases, however, are not very likely to prevail in practice.

The second model extends the first one for the case of multiple underwriting and investment activities. It is shown that constraining the leverage, per se, cannot be used as a means of constraining the probability of ruin. This goal can be achieved only by constraining both the leverage and the composition of the insurance and the investment portfolios.

The third model uses a continuous time framework and demonstrates the importance of a penalty system as a regulatory instrument. This model exposes the trade-off between the minimum capital requirements and the level of penalties, and gives some insight into the mechanism of setting the firm's and the regulatory policies.

All forms of regulation force the firms to operate in an inefficient way (otherwise, regulation will be redundant). The cost of regulation can be analysed by comparing the optimum without regulation to that reached with regulation.

The subject of regulation is very wide and could not possibly be treated from all aspects in such a short paper. A research topic which seems to be promising would be to examine the trade-off between minimum capital requirements, regulation of the portfolio composition and re-insurance. Re-insurance has been completely ignored in this paper as well as in most earlier studies on regulation. In some of the empirical studies the analysis is even carried out in terms of gross, rather than retained, premiums ! Many other forms of regulation, and the variations among countries were not touched upon. The author does hope, however, that this paper would encourage more research on this important and interesting topic.

\section{REFERENCES}

BAUMOL, W. J. [1963] : “An expected gain - confidence limit criterion for portfolio selection ", Management Science, October 1963, 174-182.

BECKMAN, R. W., and TREMELING, R. N. [1972] : "The relationship between net premium written and policyholders surplus", Proceedings of Casualty Actuarial Society 59, 203-220.

BORCH, K. [1974] : "Capital markets and the supervision of insurance companies", The Journal of Risk and Insurance 41, 397-406.

BUHLMANN, H. [1970] : Mathematical Methods in Risk Theory, Springer Verlag, Bonn.

FERRARI, J.R. [1968] : “The relationship of underwriting, investment, leverage, and exposure to total return on owners' equity", Proceedings of the Casualty Actuarial Society 55, 295-302 ; discussion by R. J. Balcarek and R. A. Bailey, 56 [1969], 58-62.

HALLIN, M. [1977] : "Band strategies: The random walk of reserves", Working Paper 3, Université Libre de Bruxelles, Institute of Statistics, December 1977.

HAMMOND, SHAPIRO and SHILLING [1978] : " The regulation of insurer solidity through capital and surplus requirements", Technical Report, NSF GRANT -16550 A01, March 1978. 
HART, O. D., and JAFFEE, D. M. [1974] : "On the application of portfolio theory to depository financial intermediaries", Review of Economic Studies 41, No. 1.

HAUGEN, R. A., and KRONCKE, C. O. [1970] : "Optimizing the structure of capital claims and assets of a stock insurance company", Journal of Risk and Insurance 37, 41-49; and "Reply" 39 [1972], 305-316.

HOFFLANDER, A.E., and DUVALL, R. M. [1967]: “The ruin problem in multiple line insurance: A simplified model ", Journal of Financial and Quantitative Analysis 2, 150-165.

JOSKOW, P.L. [1973]: "Cartels, competition and regulation in the property-liability insurance industry ", The Bell Journal of Economics and Management Science 4, 375-427.

KAHANE, Y. [1977]: "Capital adequacy and the regulation of financial intermediaries", Journal of Banking and Finance, 207-218.

KAHANE, Y. [1978] : "The theory of insurance risk premiums - A re-examination in light of recent development in capital market theory", The ASTIN Bulletin, forthcoming.

KAHANE, Y., and NYE, D. [1975]: "A portfolio approach to the property-liability insurance industry", The Journal of Risk and Insurance 42, 579-598.

KENNEY, R. [1967] : Fundamentals of Fire and Casualty Studies, The Kenedy Insurance Studies, Dedham (Mass.).

KROUSE, C. G. [1970] : "Portfolio balancing corporate assets and liabilities with special application to insurance management ", Journal of Financial and Quantitative Analysis 5, 77-105.

LEVY, H., and SARNAT, M. [1972] : Investment and Portfolio Analysis, John Wiley \& Sons, New York.

MICHAELSEN, J. B., and GOSHAY, R.C. [1967] : "Portfolio selection in financial intermediaries : A new approach ", Journal of Financial and Quantitative Analysis 2, 166-199.

NATIONAL ASSOCIATION OF INSURANCE COMMISSIONERS [1970]: Measurement of Profitability and Treatment of Investment Income in Property-Liability Insurance.

PARKIN, M. [1970] : “Discount house portfolio and debt selection ”, Review of Economic Studies 37, No. 4.

PYLE, D. H. [1971] : "On the theory of financial intermediation", Journal of Finance, 737-747.

QUIRIN, HALPERN, KALYMON, MATHEWSON and WATERS [1974]: Competition, Economic Efficiency and Profitability in the Canadian Property and Casualty Insurance Industry, prepared for the Insurance Bureau of Canada, Toronto.

ROSA, J.J., and FERRY, C. [1978] : "Effets des réglementations sur la rentabilité et le risque des compagnies d'assurances non-vie", The Geneva Association Etudes \& Dossiers 23.

TAPIERO, ZUCKERMANN and KAHANE, Y. [1978] : "Regulation of an insurance firm with a compound Poisson claim process", Tel Aviv University, Erhard Insurance Center, Working Paper. 